\title{
Transient osteoporosis of the hip and subclinical hypothyroidism: an unusual dangerous duet? Case report and pathogenetic hypothesis
}

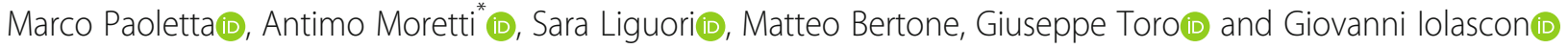

\begin{abstract}
Background: Transient osteoporosis of the hip $(\mathrm{TOH})$ is a rare and temporary clinical condition characterised by bone marrow edema (BME), severe pain, and functional limitation. It commonly occurs in middle-aged men or in women in the last trimester of pregnancy. TOH usually resolves with conservative therapy but may predispose to hip fracture or progression to avascular necrosis (AVN). Etiology is still unclear, although several pathophysiological mechanisms underpinning this condition has been proposed. We describe the management of an unusual case of $\mathrm{TOH}$ occurred in a patient with subclinical hypothyroidism.

Case presentation: A clinical case of a 46-year-old man with severe pain in the left anterior thigh is presented. After a comprehensive clinical and radiological approach, a TOH was diagnosed. Moreover, biochemical assessment suggested the presence of subclinical hypothyroidism. After 3 months of treatment with clodronate, physical therapy and hormone replacement therapy (HRT) a significant improvement of clinical and radiological outcomes was observed.

Conclusion: Several pathological conditions have been related to development of $\mathrm{TOH}$. In our case, we suggested for the first time a role of subclinical hypothyroidism as novel contributory factor for the onset of this condition, providing pathophysiological mechanisms and a scientific rationale for pharmacological treatment.
\end{abstract}

Keywords: Case report, Transient osteoporosis of the hip, Hypothyroidism, Diphosphonates, Rehabilitation

\section{Background}

Transient osteoporosis (TO) is a rare disease characterized by bone edema as main finding, so that this condition is included among the bone marrow edema syndromes (BMES) [1]. In clinical practice, BMES are commonly underestimated and referred to interchangeably as bone marrow lesions (BMLs) that are characterized by progressive musculoskeletal pain with insidious onset, usually affecting a single joint, and functional

\footnotetext{
* Correspondence: antimo.moretti@unicampania.it

Department of Medical and Surgical Specialties and Dentistry, University of Campania "Luigi Vanvitelli", Via De Crecchio 4, 80138 Naples, Italy
}

impairment with limitations of activities of daily living (ADLs) [1]. The term "BMLs" defines conditions characterized by high bone marrow signal intensity on fluidsensitive sequences on magnetic resonance imaging (MRI) [2]. This finding can be found in several traumatic, degenerative, inflammatory, vascular, metabolic, neoplastic and iatrogenic disorders [3].

Among BMLs, TO is characterized by low bone mineral density (BMD) affecting one skeletal site (such as hip or knee) and sometimes other bones [3-6]. Transient osteoporosis of the hip $(\mathrm{TOH})$ is the most prevalent TO, mainly affecting men in middle age, even

(c) The Author(s). 2020 Open Access This article is licensed under a Creative Commons Attribution 4.0 International License, which permits use, sharing, adaptation, distribution and reproduction in any medium or format, as long as you give appropriate credit to the original author(s) and the source, provide a link to the Creative Commons licence, and indicate if changes were made. The images or other third party material in this article are included in the article's Creative Commons licence, unless indicated otherwise in a credit line to the material. If material is not included in the article's Creative Commons licence and your intended use is not permitted by statutory regulation or exceeds the permitted use, you will need to obtain permission directly from the copyright holder. To view a copy of this licence, visit http://creativecommons.org/licenses/by/4.0/. The Creative Commons Public Domain Dedication waiver (http://creativecommons.org/publicdomain/zero/1.0/) applies to the data made available in this article, unless otherwise stated in a credit line to the data. 
if pregnancy is considered as the most common risk factor [7], as well as the first cause of $\mathrm{TOH}$ described in the literature [8]. However, it is essential to identify primary (idiopathic) or secondary forms of $\mathrm{TOH}$ [7], where radiological finding of BMLs could be suggestive of systemic conditions.

In this case report we describe an unusual form of $\mathrm{TOH}$ related to subclinical hypothyroidism describing clinical and diagnostic work-up as well as therapeutic management and proposing a pathophysiological hypothesis.

\section{Case presentation}

A 46-year-old Caucasian man referred to our outpatient rehabilitation service in January 2019 for spontaneous pain at the left thigh. He was $1.80 \mathrm{~m}$ tall and weighed 72 $\mathrm{kg}$ (BMI $22.2 \mathrm{~kg} / \mathrm{m}^{2}$ ). He reports a lifestyle characterized by occasional alcohol intake (less than one alcohol unit per day) and sedentary work (office worker). Medical history is significant for a trimalleolar fracture of the right ankle treated with open reduction and internal fixation in October 2011. Moreover, in July 2018 he practiced stool culture, faecal occult blood test, celiac disease screening, urinalysis, and abdominal ultrasound, because of the occurrence of several episodes of acute diarrhoea, that were responsive to a short course of antidiarrheal and antispasmodic agents and probiotics.

Clinical complaints started in January 2019 with gradually increasing groin pain without any previous trauma requiring the use of a crutch. The primary care physician prescribed oral diclofenac $150 \mathrm{mg}$ and omeprazole $20 \mathrm{mg}$ per day for 1 week, but the symptoms did not regress. Therefore, his doctor advised him to consult a physiatrist at our service.

On physical examination, patient reported severe groin pain (Numeric Rating Scale, NRS, 8/10) radiating to the antero-medial thigh and at the knee, worse during the night and weight-bearing activity. Moreover, passive and active range of motion (ROM) of the left hip (internal and external rotation $15^{\circ}$, flexion $95^{\circ}$ ) were limited and patients was forced to use walking sticks. We planned a diagnostic workup including laboratory exams, including complete blood count (CBC), serum erythrocyte sedimentation rate (ESR), C-Reactive Protein (CRP), alanine transaminase (ALT), aspartate transaminase (AST), creatinine, uric acid, alkaline phosphatase (ALP), calcium, phosphate, parathyroid hormone (PTH), 25(OH) vitamin $\mathrm{D}$, thyroid-stimulating hormone (TSH), total testosterone, protein electrophoresis, urinary free kappa and lambda light chains, and magnetic resonance imaging (MRI) scan of the hips. Laboratory tests were normal, except for increased serum TSH $(3.28 \mu \mathrm{IU} / \mathrm{ml}$, normal range $0.2-2.5 \mu \mathrm{IU} / \mathrm{ml}$ ), while remarkable and diffuse bone edema in epiphyseal and metaphyseal region of the left proximal femur was reported, supporting the diagnosis of $\mathrm{TOH}$ (Fig. 1).

Therefore, we prescribed clodronate $(200 \mathrm{mg}$ i.m. for 10 days and then $200 \mathrm{mg}$ i.m. every other day for 20 days) [9], oral calcium citrate (1 stick of $500 \mathrm{mg}$ per day for 1 month), and cholecalciferol (1 oral solution of 25, $000 \mathrm{IU}$ weekly for 1 month). Pharmacological approach was associated with instrumental physical therapy, including Pulsed Electromagnetic Fields (PEMFs) stimulation [ $8 \mathrm{~h}$ per day (night use) for 6 weeks; the device generated single-voltage pulses of 1.3 milliseconds in duration, with a frequency of $75 \mathrm{~Hz}$, and was positioned on the lateral thigh] [10-12], and Neuromuscular Electrical Stimulation (NMES) [13] of the left quadriceps (1 session per day for 3 weeks; electrodes were placed around the thigh for $30 \mathrm{~min}$ each session, generating a frequency of $50 \mathrm{~Hz}$, pulse duration of $250 \mathrm{~ms}$, and $10 \mathrm{~s}$ on and $30 \mathrm{~s}$ off). Moreover, protected weight bearing for 3 weeks was advised. Finally, we recommended a consultation with an endocrinologist to address putative thyroid disorders.

The endocrinologist performed thyroid ultrasound revealing hypoechoic nodule of $5 \mathrm{~mm}$ and new laboratory assessment confirming increased TSH levels (3.67 $\mu \mathrm{IU} /$ $\mathrm{ml}$ ) and normal level of free thyroxine, (FT4, $15.18 \mathrm{pg} / \mathrm{ml}$, normal range 6-18 pg/ml) and free triiodothyronine, (T3, $3.67 \mathrm{pg} / \mathrm{ml}$, normal range $2.57-4.43 \mathrm{pg} / \mathrm{ml}$ ). The specialist made the diagnosis of subclinical hypothyroidism and prescribed a nutraceutical containing both myo-inositol (600 mg) and selenium (83 mcg) (1 tablet per day for 2 months).

Clinical and instrumental follow-up performed after 2 months from the beginning of therapies, showed significant pain relief (NRS 2/10), improved ROM of the hip, and a significant reduction of bone edema at MRI examination of the left hip (Fig. 2). Moreover, the patient was able to walk without aids. However, due to persistent high level of TSH $(3,56 \mu \mathrm{IU} / \mathrm{ml}$, normal range $0,2-2,5$ $\mu \mathrm{IU} / \mathrm{ml}$ ), endocrinologist prescribed levothyroxine $25 \mu \mathrm{g}$ per day resulting in serum TSH reduction $(2,64 \mu \mathrm{IU} / \mathrm{ml})$ after 2 months. Finally, the patient did not report any adverse events.

\section{Discussion and conclusion}

Bone marrow lesions (BMLs) are characterized by high signal on both T2/proton density with fat suppression and short tau inversion recovery (STIR) MRI sequences with or without low signal intensity on T1-weighted images [14]. These conditions are generally defined as bone marrow edema (BME), a nonspecific MRI finding in both symptomatic and asymptomatic patients. Transient osteoporosis of the hip is included in non-traumatic BMES [14], whose pathogenic mechanisms are not well defined. Our patient is an office worker conducting a 


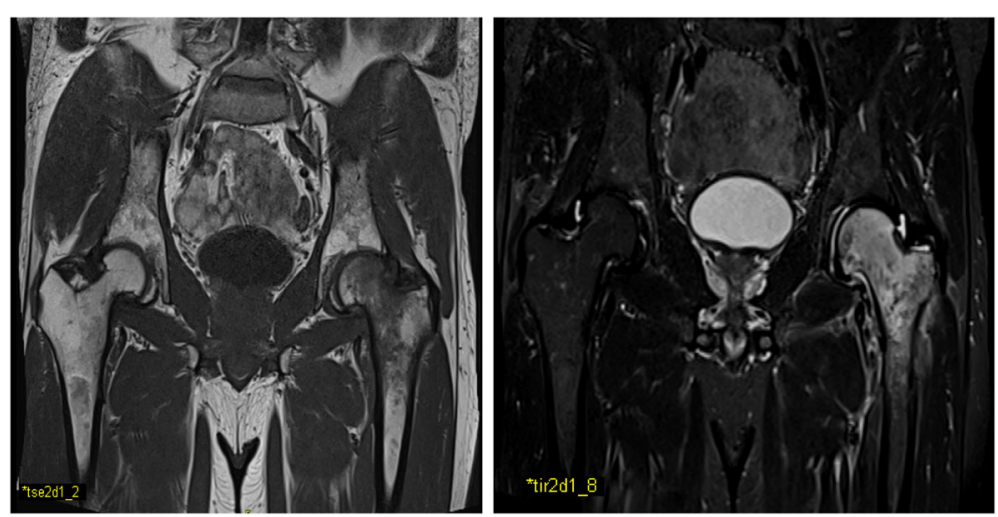

Fig. 1 Left lower limb MRI showing remarkable and diffuse bone marrow edema

sedentary lifestyle, thus suggesting a non-traumatic trigger of TOH. BMES is usually burdened by a challenging differential diagnosis [14-16], considering that trauma, infection, inflammation, degenerative process, ischemic injury, neoplasia, surgery, drugs, neurologic or metabolic disorders [7] might be associated to its occurrence. Moreover, all these conditions might contribute to impaired bone metabolism. Particularly, severe hypothyroidism negatively influences bone modeling and skeletal growth in children, whereas in adults it leads to delayed remodeling of cortical and trabecular bone because of abnormal osteoblastic and osteoclastic activity [17-20].

Some cases of $\mathrm{TOH}$ due to severe hypothyroidism have been reported in the literature. In 1938 Albright first described radiological lesions of hip simulating Legg-Perthes disease, reversible after hormone replacement therapy (HRT) in a 13-year-old hypothyroid child with growth retardation [21]. In 1959 Weissbein et al. described a case of a 22-year-old man affected by primary myxedema that referred to orthopedic service for severe pain of anterior region of the thigh to the knee aggravated by walking. Plain $\mathrm{x}$-ray demonstrated an osteolytic lesion of the right femoral head improved after HRT [22]. More recently, McLean and Podel reported a case of a 25-year-old man with severe hypothyroidism and right hip and knee pain on weight-bearing and effusion of the right hip at MRI evaluation, improving within 2 to 3 months of HRT [17]. About 15 years later, Mepani and Findling described a case of a 32-years-old man with severe primary hypothyroidism, with 3-to-4 months hip discomfort and BME of the femoral head at MRI improving at 3 months and 1 year after HRT [23].

However, the cases mentioned share the occurrence of spontaneous bone pain due to lesions at femoral head in patients with severe hypothyroidism.

On the other hand, our case is unique because the occurrence of $\mathrm{TOH}$ in a patient with subclinical hypothyroidism has not previously been described in the literature so far. We speculate that subclinical hypothyroidism may be a metabolic trigger for $\mathrm{TOH}$ as reported for severe hypothyroidism $[17,18]$, resulting in

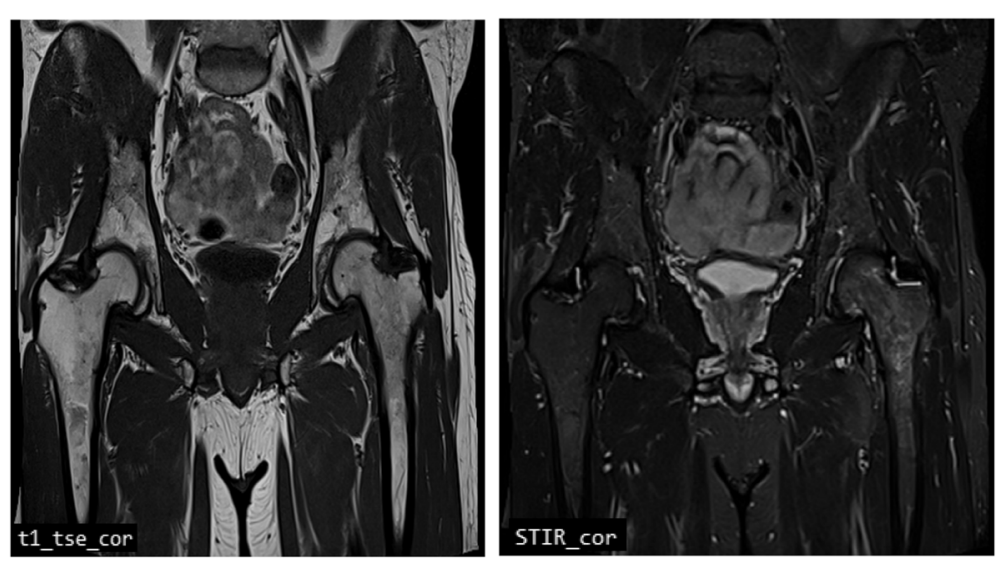

Fig. 2 Left hip MRI showing a significant reduction of bone edema at proximal femur 
fatty replacement of bone marrow [24], cellular infiltration (lymphocytes, plasma cells, histiocyte) [25], impaired blood flow (impaired venous return), local hyperemia [26-29], and pro-inflammatory milieu (cytokines) [3]. These pathways may cause a vicious circle with an increased bone turnover and acceleration of biological processes called Regional Acceleratory Phenomen (RAP) [30, 31]. The rationale for using antiresorptive drugs like bisphosphonates (BPs) could be their action on increased regional high bone turnover state, proinflammatory milieu (cytokines) and vasoactive agents, resulting in clinical and radiological improvements [3].

The role of BPs in relieving bone pain has been extensively hypothesized. Osteoclastic activity and/or bone inflammation produce an acidic microenvironment that activates specific chemoreceptors (TRVP1 and ASICs) that may be involved in the pathogenesis of pain [32, 33]. Therefore, by inhibiting osteoclast activity BPs might be effective in reducing bone pain. Moreover, in rat models, alendronate raises pain threshold, reducing the number of c-Fos + neurons (proto-oncogene expressed by neurons following both nociceptive and non-nociceptive stimuli) in lamina 1 and 2 of the dorsal horns of the spinal cord [34]. Also, the release of substance P and other neuropeptides may be implicated in mechanisms of bone pain. In a rat model of sciatic nerve injury, it has been hypothesized that substance P may be implicated even in BMD changes [35]. Bisphosphonates may reduce levels of substance $P$ via the TNF- $\alpha$ pathway playing a key role in inflammatory pain transmission by primary sensory nerves [36-38]. Among BPs, clodronate seems to have peculiar anti-inflammatory activity thanks to its intracellular metabolites (such as AppCCl $\mathrm{Cl}_{2} \mathrm{p}$ produced by RAW 264 macrophages) acting on cytokines and NO release reducing DNA binding activity of NF-kB [39].

Alongside anti-resorptive and anti-inflammatory action, analgesic mechanisms of clodronate have been proposed. This non-nitrogen-containing BPs (non-N-BPs) blocks phosphate transporter family SLC17 and inhibits vesicular transporters of ATP and/or glutamate [40]. Hydrolyzed products of ATP and ATP released in extracellular environment stimulate purinoceptors (P2X or P2Y and $\mathrm{P} 1$ adenosine receptor) on peripheral sensory nerves involved in pain transmission and modulation. Clodronate is a presynaptic blocker of vesicular ATP release from neurons that might decrease neuropathic and inflammatory pain by slowing down purinergic chemical transmission [41].

On the other hand, anti-resorptive effects of clodronate depends by intracellular accumulation of toxic ATP analogs [42, 43] and inhibition of mitochondrial ATP translocases [44] in osteoclasts resulting in their apoptosis.

Anti-resorptive, anti-inflammatory and analgesic properties of clodronate make it a viable strategy to manage
BMES and several studies have evaluated its efficacy in these conditions. In two RCTs, daily intravenous clodronate $(300 \mathrm{mg}$ daily for 10 or 12 consecutive days) has been investigated to treat algodystrophy with clinical recovery in 1-2 months [38]. The same dosing regimen was used in three patients with $\mathrm{TOH}$ followed by physical therapy (3 weeks of flexibility exercises) with clinical recovery and BMD improvement at 3-4 months [45]. Similar results were reported in a 30-year-old woman with $\mathrm{TOH}$ using clodronate in association with calcium and vitamin D supplementation after 2 months [46].

Even if this therapeutic protocol seems to be commonly suggested for BMES [7], recently, some authors assert that a global dose of $3000 \mathrm{mg}$ of clodronate would appear insufficient [9]. In our case we used for the first time intramuscular clodronate for the management of $\mathrm{TOH}$. Our protocol consists of intramuscular clodronate at the dose of $200 \mathrm{mg}$ daily for 10 consecutive days and followed by $200 \mathrm{mg}$ every other day for 20 days reaching a total dose of $4000 \mathrm{mg}$, as proposed by Frediani et al. $[9,47]$.

However, clodronate and other BPs must be carefully administered in patients with low serum ALP, commonly noticed in patients with severe hypothyroidism [18], because of higher risk of atypical femoral fractures as reported for patients with hypophosphatasia [48]. Our patient had normal serum serum ALP (68.3 U/l, normal range 40-129 U/l) that allows to administer BPs safely.

We combined instrumental physical therapy with pharmacological treatment for the first time in the management of $\mathrm{TOH}$. It has been hypothesized that PEMFs may preserve subchondral bone from marrow edema and stimulate osteogenic activity reducing the risk of trabecular fracture in femoral head osteonecrosis [12]. Moreover, PEMFs may promote bone formation, antioxidant and adenosine receptors synthesis reducing proinflammatory cytokines in CRPS I [49]. Concerning NMES, encouraging results were also reported in reducing pain after 6 weeks in patients with osteonecrosis of the femoral head [13].

Based on the available evidence, we assumed that combining PEMFs, NMES and clodronate may have been a suitable treatment strategy for our case of $\mathrm{TOH}$.

Thyroid HRT would seem to be an effective approach in patient with $\mathrm{TOH}$ and severe hypothyroidism [17, 21-23]. However, in our case we used promptly a higher dose of clodronate $(4000 \mathrm{mg}$ in 1 month). Only belatedly endocrinologist added levothyroxine, when bone edema already seemed in resolution.

We postulate that a multimodal intervention based on the use of clodronate and physical therapy could 
improve the clinical outcome in patients with $\mathrm{TOH}$ caused by subclinical hypothyroidism. In conclusion, $\mathrm{TOH}$ is suggestive of abnormal bone metabolism. Diagnostic process has a pivotal role for revealing secondary forms of TOH. Starting an appropriate and timely intervention is mandatory for a complete recovery from $\mathrm{TOH}$ to avoid the progression towards avascular necrosis of the hip.

\section{Abbreviations}

TO: Transient osteoporosis; TOH: Transient osteoporosis of the hip; BME: Bone marrow edema; AVN: Avascular necrosis; HRT: Hormone replacement therapy; BMES: Bone marrow edema syndromes; BML: Bone marrow lesion; ADL: Activities of daily living; BMI: Body mass index; MRI: Magnetic resonance imaging; BMD: Bone mineral density; NRS: Numeric Rating Scale; ROM: Range of motion; CBC: Complete blood count; ESR: Erythrocyte sedimentation rate; CRP: C-Reactive Protein; ALT: Alanine transaminase; AST: Aspartate transaminase; ALP: Alkaline phosphatase; PTH: Parathyroid hormone; TSH: Thyroid-stimulating hormone; IU: International unit; i.m.: Intramuscular injection; PEMF: Pulsed Electromagnetic Field; NMES: Neuromuscular Electrical Stimulation; STIR: Short tau inversion recovery; RAP: Regional Acceleratory Phenomen; BPs: Bisphosphonates; TRVP1: Transient receptor potential cation channel subfamily V member 1; ASICs: Acid-sensing ion channels;

AppCCl2p: Adenosine 5'-(beta,gamma-dichloromethylene) triphosphate; TNFa: Tumor necrosis factor-a; NO: Nitric oxide; NF-kB: Nuclear factor kappalight-chain-enhancer of activated B cells; ATP: Adenosine triphosphate; SLC: Solute carrier family 17; RCT: Randomized controlled trial

\section{Acknowledgments}

None.

\section{Authors' contributions}

MP, AM, and GI designed the report; MP, SL, GT, and MB collected the patient's clinical data; AM, MP, and MB analyzed the clinical data and drafted the paper. All authors read and approved the final manuscript.

\section{Funding}

The authors would like to acknowledge the Vanvitelli per la Ricerca (VALERE) program for the allocation of funding that aims to publish University of Campania "Luigi Vanvitelli" research products.

\section{Availability of data and materials}

The data that support the findings of this study are available from the corresponding author upon reasonable request.

\section{Ethics approval and consent to participate}

This study was conducted in accordance with the ethical standards as laid down in the Declaration of Helsinki and its later amendments. Written informed consent was obtained from the patient to participate in the study.

\section{Consent for publication}

Written informed consent was obtained from the patient for publication of this case report and any accompanying images.

\section{Competing interests}

The authors have no conflicts of interest to disclose.

Received: 8 April 2020 Accepted: 6 August 2020

Published online: 13 August 2020

\section{References}

1. Patel S. Primary bone marrow oedema syndromes. Rheumatology. 2014;53: 785-92. https://doi.org/10.1093/rheumatology/ket324.

2. Kon $E$, Ronga $M$, Filardo $G$, et al. Bone marrow lesions and subchondral bone pathology of the knee. Knee Surg Sports Traumatol Arthrosc. 2016; 24(6):1797-814. https://doi.org/10.1007/s00167-016-4113-2.
3. Eriksen EF, Ringe JD. Bone marrow lesions: a universal bone response to injury? Rheumatol Int. 2012;32(3):575-84. https://doi.org/10.1007/s00296011-2141-2.

4. Emad Y, Ragab Y, El-Shaarawy N, Rasker JJ. Transient osteoporosis of the hip, complete resolution after treatment with alendronate as observed by MRI description of eight cases and review of the literature. Clin Rheumatol. 2012;31:1641-7.

5. Guardiano SA, Katz J, Schwartz AM, Brindle K, Curiel R. Fracture complicating the bone marrow edema syndrome. J Clin Rheumatol. 2004;10:269-74.

6. O'Sullivan SM, Grey AB, Singh R, Reid IR. Bisphosphonates in pregnancy and lactation-associated osteoporosis. Osteoporos Int. 2006;17:1008-12.

7. Asadipooya K, Graves L, Greene LW. Transient osteoporosis of the hip: review of the literature. Osteoporos Int. 2017;28(6):1805-16. https://doi.org/ 10.1007/s00198-017-3952-0.

8. Curtiss PH Jr, Kincaid WE. Transitory demineralization of the hip in pregnancy. A report of three cases. J Bone Joint Surg Am. 1959;41-A: 1327-33.

9. Frediani B, Giusti A, Bianchi G, et al. Clodronate in the management of different musculoskeletal conditions. Minerva Med. 2018;109(4):300-25. https://doi.org/10.23736/S0026-4806.18.05688-4.

10. Martinelli N, Bianchi A, Sartorelli E, Dondi A, Bonifacini C, Malerba F. Treatment of bone marrow edema of the talus with pulsed electromagnetic fields: outcomes in six patients. J Am Podiatr Med Assoc. 2015;105(1):27-32. https://doi.org/10.7547/8750-7315-105.1.27.

11. Leo M, Milena F, Ruggero C, Stefania S, Giancarlo T. Biophysical stimulation in osteonecrosis of the femoral head. Indian J Orthop. 2009;43(1):17-21. https://doi.org/10.4103/0019-5413.45319.

12. Massari L, Fini M, Cadossi R, Setti S, Traina GC. Biophysical stimulation with pulsed electromagnetic fields in osteonecrosis of the femoral head. J Bone Joint Surg Am. 2006;88(Suppl 3):56-60.

13. Ji QH, Qiao XF, Wang SF, et al. Effectiveness of neuromuscular electrical stimulation and ibuprofen for pain caused by necrosis of the femoral head: a retrospective study. Medicine (Baltimore). 2019;98(11):e14812. https://doi. org/10.1097/MD.0000000000014812.

14. Klontzas ME, Zibis AH, Vassalou EE, Karantanas AH. MRI of the hip: current concepts on bone marrow oedema. Hip Int. 2017;27(4):329-35. https://doi. org/10.5301/hipint.5000527.

15. Klontzas ME, Vassalou EE, Zibis AH, Bintoudi AS, Karantanas AH. MR imaging of transient osteoporosis of the hip: an update on 155 hip joints. Eur J Radiol. 2015;84(3):431-6.

16. Klontzas ME, Zibis AH, Karantanas AH. Osteoid osteoma of the femoral neck: use of the half-moon sign in MRI diagnosis. AJR Am J Roentgenol. 2015; 205(2):353-7.

17. McLean RM, Podell DN. Bone and joint manifestations of hypothyroidism. Semin Arthritis Rheum. 1995;24(4):282-90.

18. Mosekilde L, Eriksen EF, Charles P. Effects of thyroid hormones on bone and mineral metabolism. Endocrinol Metab Clin N Am. 1990;19(1):35-63.

19. Eriksen EF. Normal and pathological remodeling of human trabecular bone: three dimensional reconstruction of the remodeling sequence in normals and in metabolic bone disease. Endocr Rev. 1986;7(4):379-408.

20. Eriksen EF, Mosekilde L, Melsen F. Kinetics of trabecular bone resorption and formation in hypothyroidism: evidence for a positive balance per remodeling cycle. Bone. 1986;7(2):101-8.

21. Albright F. Changes simulating Legg-Perthes disease due to juvenile myxoedema. J Bone Joint Surg. 1938;20:764-9.

22. Weissbein AS, Darby JP Jr, Lawson JD. An unusual bone lesion in an adult with myxedema. Report of a case and review of the literature. Arch Intern Med. 1959;104:643-8.

23. Mepani JB, Findling JW. Reversible bone marrow edema of the hip due to severe hypothyroidism. J Clin Endocrinol Metab. 2009;94(4):1068.

24. Zanetti M, Bruder E, Romero J, Hodler J. Bone marrow edema pattern in osteoarthritic knees: correlation between MR imaging and histologic findings. Radiology. 2000;215:835-40.

25. Axelrod AR, Berman L. The bone marrow in hyperthyroidism and hypothyroidism. Blood. 1951;6(5):436-53.

26. Rosen RA. Transitory demineralization of the femoral head. Radiology. 1970; 94:509-12.

27. Hofmann S, Engel A, Neuhold A, Leder K, Kramer J, Plenk H Jr. Bone-marrow oedema syndrome and transient osteoporosis of the hip: an MRI-controlled study of treatment by core decompression. J Bone Joint Surg (Br). 1993;75B:210-6. 
28. Arnstein RA. Regional Osteoporosis. Orthop Clin North Am. 1972;3:585-600

29. Bray ST, Partain CL, Teates CD, Guilford WB, Williamson BR, McLaughlin RC. The value of the bone scan in idiopathic regional migratory osteoporosis. J Nucl Med. 1979;20:1268-71.

30. Trevisan C, Ortolani S, Monteleone M, Marinoni EC. Regional migratory osteoporosis: a pathogenetic hypothesis based on three cases and a review of the literature. Clin Rheumatol. 2002;21(5):418-25.

31. Frost HM. Perspectives: bone's mechanical usage windows. Bone Miner. 1992;19:257-71

32. Bonabello A, Galmozzi MR, Bruzzese T, Zara GP. Analgesic effect of bisphosphonates in mice. Pain. 2001;91(3):269-75.

33. Varenna M, Adami S, Sinigaglia L. Bisphosphonates in complex regional pain syndrome type I: how do they work? Clin Exp Rheumatol. 2014;32(4):451-4 Epub 2014 Jun 24.

34. Abe Y, Iba K, Sasaki K, et al. Inhibitory effect of bisphosphonate on osteoclast function contributes to improved skeletal pain in ovariectomized mice. J Bone Miner Metab. 2015;33(2):125-34. https://doi.org/10.1007/ s00774-014-0574-x Epub 2014 Mar 16.

35. Gaus K, Moriwaki H, Suyama M, Kawamoto M, Yuge O. Capsaicin treatment inhibits osteopenia and heat hyperalgesia induced by chronic constriction injury to the sciatic nerve in rats. Hiroshima J Med Sci. 2003;52:43-51.

36. Ohtori S, Akazawa T, Murata Y, et al. Risedronate decreases bone resorption and improves low back pain in postmenopausal osteoporosis patients without vertebral fractures. J Clin Neurosci. 2010;17(2):209-13. https://doi. org/10.1016/j.jocn.2009.06.013 Epub 2009 Dec 30.

37. Van Offel JF, Schuerwegh AJ, Bridts CH, Bracke PG, Stevens WJ, De Clerck LS, Influence of cyclic intravenous pamidronate on proinflammatory monocytic cytokine profiles and bone density in rheumatoid arthritis treated with lowdose prednisolone and methotrexate. Clin Exp Rheumatol. 2001;19:13-20.

38. Varenna M, Zucchi F, Ghiringhelli D, et al. Intravenous clodronate in the treatment of reflex sympathetic dystrophy syndrome. A randomized, double blind, placebo controlled study. J Rheumatol. 2000;27:1477-83.

39. Makkonen N, Salminen A, Rogers MJ, et al. Contrasting effects of alendronate and clodronate on RAW 264 macrophages: the role of a bisphosphonate metabolite. Eur J Pharm Sci. 1999:8(2):109-18.

40. Shima K, Nemoto W, Tsuchiya M, et al. The bisphosphonates clodronate and etidronate exert analgesic effects by acting on glutamate- and/or ATPrelated pain transmission pathways. Biol Pharm Bull. 2016;39(5):770-7. https://doi.org/10.1248/bpb.b15-00882.

41. Moriyama Y, Nomura M. Clodronate: a vesicular ATP release blocker. Trends Pharmacol Sci. 2018;39(1):13-23. https://doi.org/10.1016/j.tips.2017.10.007 Epub 2017 Nov 13.

42. Rogers MJ. New insights into the molecular mechanisms of action of bisphosphonates. Curr Pharm Des. 2003;9:2643-58.

43. Ghinoi V, Brandi ML. Clodronate: mechanisms of action on bone remodelling and clinical use in osteometabolic disorders. Expert Opin Pharmacother. 2002;3:1643-56.

44. Lehenkari PP, Kellinsalmi M, Näpänkangas JP, et al. Further insight into mechanism of action of clodronate: inhibition of mitochondrial ADP/ATP translocase by a nonhydrolyzable, adenine-containing metabolite. Mol Pharmacol. 2002;61:1255-62.

45. Varenna M, Sinigaglia L, Binelli L, Beltrametti P, Gallazzi M. Transient osteoporosis of the hip: a densitometric study. Clin Rheumatol. 1996;15(2): 169-73.

46. Schapira D, Braun Moscovici Y, Gutierrez G, Nahir AM. Severe transient osteoporosis of the hip during pregnancy. Successful treatment with intravenous biphosphonates. Clin Exp Rheumatol. 2003;21(1):107-10

47. Frediani B, Bertoldi I. Clodronate: new directions of use. Clin Cases Miner Bone Metab. 2015;12:97-108.

48. Righetti M, Wach J, Desmarchelier R, Coury F. Teriparatide treatment in an adult patient with hypophosphatasia exposed to bisphosphonate and revealed by bilateral atypical fractures. Joint Bone Spine. 2018;85(3):365-7. https://doi.org/10.1016/j.jbspin.2017.12.001 Epub 2017 Dec 12.

49. Pagani S, Veronesi F, Nicoli Aldini N, Fini M. Complex regional pain syndrome type I, a debilitating and poorly understood syndrome. Possible role for pulsed electromagnetic fields: a narrative review. Pain Physician. 2017;20:E807-22.

\section{Publisher's Note}

Springer Nature remains neutral with regard to jurisdictional claims in published maps and institutional affiliations.

\section{Ready to submit your research? Choose BMC and benefit from}

- fast, convenient online submission

- thorough peer review by experienced researchers in your field

- rapid publication on acceptance

- support for research data, including large and complex data types

- gold Open Access which fosters wider collaboration and increased citations

- maximum visibility for your research: over $100 \mathrm{M}$ website views per year

At BMC, research is always in progress.

Learn more biomedcentral.com/submissions 